\title{
PENERAPAN TEKNOLOGI COMPUTER GENERATED IMAGERY PADA VISUAL EFFECT FILM
}

\author{
Dewi Immaniar ${ }^{1}$ \\ Lusyani Sunarya $^{2}$ \\ Muhammad Alfian ${ }^{3}$ \\ Email : dewi.immaniar@raharja.info, lusyani@raharja.info, alfian@raharja.info
}

\begin{abstract}
In modern times such as this, the world of entertainment, especially in the film really enjoy doing. Various types of films emerging and very interesting to watch. In the modern era of telecommunications today, technology is very influential. Mainly in the manufacture of various films. Start of animas to fiction films. At that moment the application of multimedia technology of computer generated imagery is needed, to make a movie that the film will be alive and visible. In the filming of Transformers lot of computer generated imagery using this technology, because of the effects of a car that turns into a robot is not possible using the manual method such as dressing sets per set of movie. Therefore Computer Generated Imagery is used this technology. In the atmosphere of the original, just needed the room with the green screen background and then will be processed into a computer and software specifications are quite high. Starting from the effects of flying to the moon, meteor fall, the transformation changes the shape and use CGI effects, because otherwise the result would not be perfect. Thus the CGI technology is not only used in the Transformers movie pebuatan alone, but also on the making of the film to make it look more stunning and cool.
\end{abstract}

Keywords : Mutimedia, Computer Generated Imagery, Software, Computer, Technology

\begin{abstract}
ABSTRAK
Di zaman modern seperti saat ini, dunia hiburan khususnya pada film sangat di gemari. Berbagai jenis film bermunculan dan sangat menarik untuk di tonton. Di era modern telekomunikasi saat ini, teknologi sangat berpengaruh. Seiring berkembangnya teknologi yang sangat maju tidak di imbangi dengan pengadaan fasilitas pembuatan film. Sehingga kadang dalam proses pembuatan film akan terjadi kesalahan bahkan cendrung film akan menjadi tidak bagus. Dengan menggunakan teknologi Computer Generated Imagery memungkinkan pembuatan film akan berjalan dengan baik. Multimedia yang di tampilkan akan sesuai dengan skenario dan sesuai dengan kebutuhan pada tahap produksi. Dalam artikel ini, di identifikasi permasalahannya adalah dalam pembuatan film Transformers jika tidak menggunakan CGI, dampak pengeluaran biaya aka menjadi besar, pengertian dari Computer Generated Imagery tersebut, keuntungan dan kelemahan menggunakan teknologi CGI, serta manfaat dalam pengunaan metode CGI ini. Pada implementasinya, pengguna teknologi CGI ini akan berdampak positif pada pembuatan film yang banyak menggunakan visual efek. Teknologi CGI ini berandil besar dalam pengembangan dunia perangkat lunak maupun keras pada dunia komputer, dan menjadi solusi dalam pembuatan film dengan aksi dan efek yang memukau.
\end{abstract}

Kata Kunci : Multimedia, Computer Generated Imagery, Teknologi

Vol.1 No.1 - Agustus 2015 


\section{PENDAHULUAN}

Dengan berjalannya waktu, dan berkembangnya teknologi komputer sebuah film bisa dibuat dengan mudah dan lebih menghemat waktu. Terutama jika menggunakan teknologi CGI ini. Jika tidak ada teknologi ini, mungkin akan membutuhkan waktu yang sangat lama untuk membuat satu film.Teknologi CGI ini juga termasuk teknologi yang sudah lama namun belum berkembang seperti saat ini. Dimana setiap adegan film hampir menggunakan CGI, bahkan ada juga yang menggunakan dengan Full CGI. Tidak bisa dipungkiri teknologi CGI ini sangat berpengaruh dan membuat sebuah film menjadi terkenal dan bisa dibuat sekuel berikutnya. Alur cerita dan teknologi yang modern menyatu dan membuat karya yang menggagumkan.

Film Transformers ini cukup banyak menggunakan teknologi CGI. Mulai dari desain perubahan mobil menjadi robot. Pertama harus membuat desain pada software 3ds Max lalu dibuat dibuat grafisnya dan diproses melalui green screen. Dalam pembuatan film Transformers ini efek-efek yang ditampilkan seperti nyata, dan suara yang dihasilkan pun jernih. Dalam pembuatan film Transformers ini tidak mudah, harus membutuhkan kejelian dan harus teliti. Karena detail yang dibiaut harus sedemikian rupa asli dan halus agar tidak terjadi kesalahan pada saat proses render. Pada awal pembuatan Film Transformers yang pertama cukup menggagumkan karena efek yang dihasilkan begitu nyata dan seperti hidup.

Setelah sukses membuat film pertamanya, Transformers membuat sekuel keduanya yang berjudul Transformers 2 : Revenge The Fallen. Di flm kedua ini, efek yang digunakan dalam green screen cukup banyak. Dimana adegan Fallen musuh Optimis Prime hidup dan berusaha menhancurkan

Vol.1 No.1 - Agustus 2015 bumi. Ada adegan dimana perjalanan mengarungi galaksi, tidak mungkin dilakukan tanpa menggunakan efek green screen ini. Efek mulai dari benturan, meteor jatuh, semua dibuat dalam proses syuting di green screen. Selanjutnya sang sutradara Michael Bay merilis sekuel ketiga Trasnformers yaitu, Transformers 3 : Dark Of The Moon. Dan film ini sukses, culup mengaggumkan dan banyak menggunakan efek-efek yang susah dijelaskan dengan logika manusia.

Dalam pembuatan film Transformers ini CGI atau Computer Generated Imagery sangat dibutuhkan. Bayangkan jika tidak menggunakan teknologi CGI ini, mungkin film yang bagus ini tidak akan sukses dan jarang ditonton. Dari sinilah peran CGI dibutuhkan, karena efek yang bagus dan jernih bisa dihasilkan oleh teknologi yang tinggi. Animasi CGI adalah proses yang digunakan untuk menghasilkan gambar animasi yang secara keseluruhan menggunakan bantuan komputer grafis. Komputergenerated imagery adalah istilah yang umum digunakan untuk membuat adegan statis dan gambar dinamis, sedangkan animasi komputer hanya mengacu pada gambar bergerak yang dibuat menggunakan komputer. Ciri dari animasi jenis ini adalah film-film berjenis 3 dimensi dimana komputer sepenuhnya digunakan dalam pembuatan seluruh film mulai dari pembuatan karakter, efek cahaya, warna, suara hingga finishing akhir (rendering). Setiap rendering membutukan waktu yang cukup banyak dan panjang. Belum lagi untuk menyatukan gambar frame by frame yang cukup sulit dan memakan waktu yang lama.

\section{PERMASALAHAN}

Bagaimana cara penerapan Teknologi CGI ini pada Film Transformers maupun film-film yang lain, yang membutuhkan 
teknologi CGI dan efek-efek yang hanya ada dalam teknologi CGI ini. Bagaimana cara kerja atau proses pembuatan film dalam teknologi CGI ini, agar semua orang tahu proses pembuatan film yang bagus dan menarik perhatian untuk dinikmati dalam dunia hiburan. Jika dalam pembuatan film Transformers tidak menggunakan teknolog CGI ini, maka tidak di pungkiri akan terjadi banyak masalah seperti biaya pembuatan film akan bertambah besar, hasil dari proses editing yang hanya meggunakan software atau perangkat lunak. Dengan hanya menggunakan software tanpa di imbangi dengan penggunaan teknologi hardware maka hasil yang di akan di tampilkan akan menjadi kurang menarik. Dan memakan waktunya lama pada tahap produksinya. Berikut ini adalah tahapan pada produksi pembuatan film ;

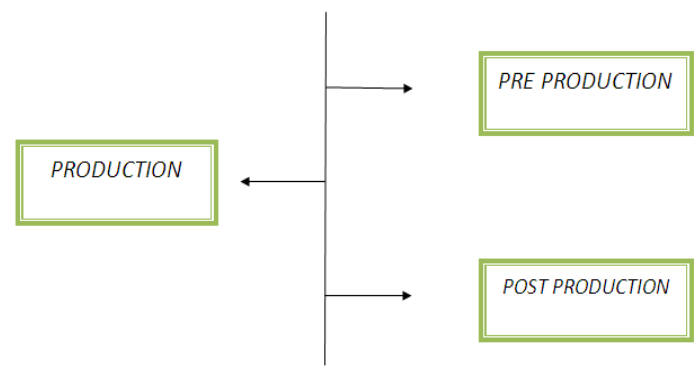

Gambar 1. Konsep Produksi Media(KPM)

Dari gambar 1. di atas di jelaskan pengertian dari Konsep produksi media yang dijlaskan pada jurnal " KPM SEBAGAI PEDOMAN PRODUKSI MULTIMEDIA AUDIO VISUAL AND BRODACASTING " yang disusun oleh Untung Rahardja dan rekan adalah dimana semua tahap sebuah film atau produksi akan dimulai. Pada tahap ini membutuhkan perencanaan yang cukup matang, seperti penyusunan naskah, pembuatan skenario dan pembuatan time schedule. Dan juga pembuatan storyboard, synopsis untuk kelancaran dalam pembuatan sebuah film fiksi Transformers. Setelah itu baru ditentukan alat-alat yang akan di gunakan lalu pemainnya, dan crew yang ikut serta dalam pembuatan produksi ini. Kemudian dilanjutkan dengan pengumpulan data melalui observasi dan wawancara dengan pihak terkait, lalu persiapan konsep dimulai dari dituangkannya ide - ide bagaimana memberikan tontonan informasi yang menarik bagi audience. production adalah sebuah produksi yang sudah memasuki tahap penyusunan dan pengeditan dan menghasilkan sebuah project video. Dalam tahapan ini kerjasama antara crew dan talent untuk perwujudan hasil rumusan dari story board, naskah, skenario yang telah di buat pada tahap pre production sebelumnya. Dan Postproduction adalah tahap terakhir dari semua proses yang sebelumnya. Dari proses awal preproduction, lalu masuk tahap production, dan berakhir di tahap postproduction. Pada tahap postproduction ini terdapat terdapat proses digitalizing, editing, mixing, finishing, art directing dan designing. Dengan adanya tahap terakhir ini, diharapkan target yang akan dicapai akan terwujud dan terlaksana.

\section{LITERATUR REVIEW}

Banyak penelitian yang sebelumnya dilakukan mengenai Visual effect. Dalam upaya pengembangan Computer Generated Imagery ini perlu dilakukan studi pustaka sebagai salah satu dari penerapan metode penelitian yang akan dilakukan. Diantaranya adalah mengidentifikasikan kesenjangan (identify gaps), menghindari pembuatan ulang (reinventing the wheel), mengidentifikasikan metode yang pernah dilakukan, meneruskan penelitian sebelumnya, serta mengetahui orang lain yang spesialisasi dan area penelitiannya sama dibidang ini. Beberapa Literature review tersebut adalah sebagai berikut : 
1 . Menurut jurnal Wahyu Hidayat dan rekan, yang berjudul " PERANCANGAN MEDIA VIDEO INTERIOR BERBENTUK ANIMASI DENGAN MENGGUNAKAN 3DS MAX “ menjelaskan bahwa, Desain Interior dan dekorasi selama ini sering terjadi kesamaan dimana keduanya seperti dalam suatu profesi yang sama. Karena keduanya sama-sama memiliki yang sama yaitu ingin memberikan rasa rasa keindahan dan kenyaman di setiap ruangan. Dekorasi Interior hanya bagian kecil dari tugasnya seorang desainer interior.Desainer interior dan dekorator. Dalam jurnal ini juga menjelaskan cara penggunaan 3DS MAX dalam mendesain suatu sebuah karakter. Dengan penelitian ini kita dapat mengembangkan animasi dan spesial efek yang akan di gunakan dalam pembuatan film.[5]

2. Menurut jurnal Maimunah dan rekan, yang berjudul " DESAIN COMPANY PROFLE INTERAKTIF SEBAGAI MEDIA INFORMASI DAN PROMOSI BERBASIS WEB APKIKASI DAN CD INTERAKTIF " menjelaskan bahwa, seiring dengan kemajuan teknologi multimedia khususnya pada bidang komunikasi memaksa kita untuk mengikuti perkembangan teknologi tersebut. Saat ini dunia mutimedia sudah banyak dikenal orang. Dalam jurnal ini menjelaskan bahwa teknologi sudah diterapkan dalam dunia film dan multimedia. Dengan mengembangkan penelitian dari artikel ini kita bisa mengetahui media informasi yang tepat untuk perancangan dalam pembuatan film.[6]

3. Menurut buku yang di tulis oleh James Monaco dengan judul "HOW TO READ A FILM:MOVIES, MEDIA, AND BEYOND: MOVIES, MEDIA, AND BEYOND " menjelaskan bahwa, Setelah memeriksa hubungan dekat film media narasi lain seperti novel, lukisan, fotografi, televisi, dan bahkan musik, buku ini membahas elemen yang diperlukan untuk memahami bagaimana film menyampaikan makna, dan, yang lebih penting, bagaimana kita bisa menjadi yang terbaik dan melihat semua yang mencoba untuk berkomunikasi. Selain itu, film menekankan konteks yang masih berkembang digital film di seluruh salah satu bagian baru terlihat pada sifat dipercaya gambar digital dan suara dan bab tentang multimedia yang membawa kritik media ke dalam abad kedua puluh satu dengan menyeluruh dengan diskusi topik seperti virtual reality, dunia maya, dan kedekatan keduanya untuk film. Dengan penelitian ini, mengajarkan sebuah cara membuat film dan membaca film pada teknologi yang berbasis pada komputer canggih.[10]

4. Menurut buku yang ditulis oleh A.J. Mitchell dalam bukunya yang berjudul " VISUAL EFFECT FOR FILM AND TELEVISION ", menjelaskan bahwa, dalam penerapan pada pembuatan film sangat berpengaruh pada hasil dan efek yang diciptakan. Membuat film tidak hanya dalam menghadirkan adegan yang nyata namun juga penerapa teknologi Computer generatde Imagery. Dengan penelitian yang ada dalam buku ini dapat digunakan untuk pembuatan film dengan visual efek yang menggumkan dan efek0-efek lain pada televisi.[9]

5. Menurut buku yang disusun oleh, Frederic P. Miller, Agnes F. Vandome, John McBrewster yang berjudul "COMPUTER-GENERATED

IMAGERY: COMPUTER GRAPHICS, 3D COMPUTER GRAPHICS, SPECIAL EFFECT, FILM, TELEVISION PROGRAM, TELEVISION ADVERTISEMENT, SIMULATION, VIDEO GAME, CUTSCENE " menjelaskan bahwa, Computer-generated imagery (juga dikenal sebagai CGI) adalah penerapan bidang komputer grafis atau, lebih 
khusus, komputer grafis 3D untuk efek khusus dalam film, program televisi, iklan, simulator dan simulasi umumnya, dan media cetak. Video game biasanya menggunakan komputer grafis real-time. Dengan penelitian yang ada dalam buku ini dapat di simpulkan bahwa penggunaan 3D spesial efek dalam film memang sangat dibutuhkan agar film menjadi lebih bagus dan menarik.[8]

6. Menurut jurnal Untung Rahardja dan rekan, yang berjudul " KPM SEBAGAI PEDOMAN PRODUKSI MEDIA MULTIMEDIA AUDIO VISUAL AND BROADCASTING " menjelaskan bahwa, perancangan suatu media periklanan dalam kebutuhan promosi produk apapunsama seperti halnya membangun sebuah bangunan yang mempunyai kualitas yang maksimal. Tanpa persiapan konstruksi yang baik mustahil untuk membangun sebuah bangunan yang hasilnya berkualitas. [12]

\section{Pembahasan}

\section{Pengertian Teknologi}

Menurut Miarso (2007 : 62) teknologi adalah proses yang meningkatkan nilai tambah, proses tersebut menggunakan atau menghasilkan suatu produk, produk yang dihasilkan tidak terpisah dari produk lain yang telah ada, dan karena itu menjadi bagian integral dari suatu sistem. Teknologi semakin modern dan canggih,tentunya para penciptanya akan terus mengembangkan teknologi agar mampu membantu pekerjaan manusia[7]. Menurut jurnal yang di tulis Maimunah dan rekan menjelaskan video dalam tahap pembuatan film dan juga penggunaan teknologi-teknologi yang canggih.Video yang berkaitan dengan interaktif yang dilakukan oleh penguna komputer. Teknologi juga berkembang dalam semua bidang, dari bidang hiburan, musik, kesehatan, militer, perkantoran dan lainlain. Tekno;ogi dalam industri perfilman cukup besar dampaknya. Karena setiap film membutuhkan teknologi yang berbasis CGI ini, maka dari situlah CGI berkembang dari waktu ke waktu. Teknologi berkembang cukup pesat di zaman informasi seperti ini. Eksperimen pun banyak bermunculan, seperti melakukan perjalanan ke luar angkasa yang di pimpin oleh NASA maupun meneliti inti bumi dengan melakukan perjalanan menuju perut bumi. Dengan penerapan Computer Generated Iamgery dapat membantu dalam proses pembuatan film. Sejarah Computer generated imagery sejalan dengan sejarah komputer itu sendiri. Kedatangan generasi ketiga dari komputer di tahun 1960-an membuka jalan bagi percobaan pertama dengan efek CGI.

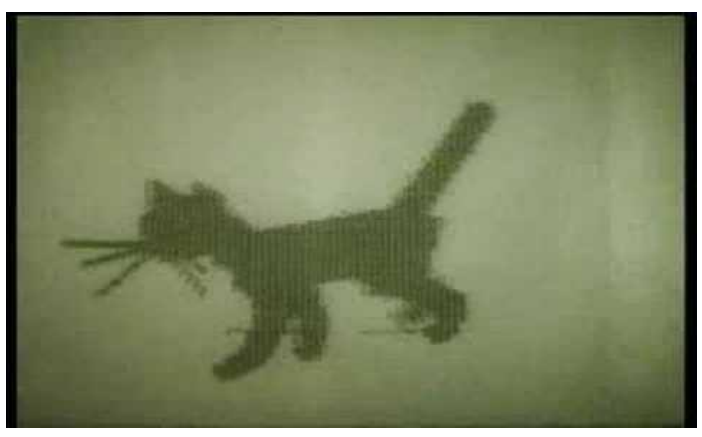

Gambar 2. bayangan CGI kucing

Untuk asal-usul komputer-generated imagery (CGI), kita perlu kembali ke tahun 1968. Pada tahun ini sekelompok Rusia matematikawan dan fisikawan dipimpin oleh N.Konstantinov menciptakan model matematika inovatif yang memungkinkan mereka untuk bergerak kucing di layar . Para ilmuwan mengembangkan model matematika mereka ke dalam program untuk komputer dengan nama BESM-4. The BESM-4 komputer mampu mencetak ratusan frame yang dapat dikonversi menjadi bahan film digunakan.[3] 


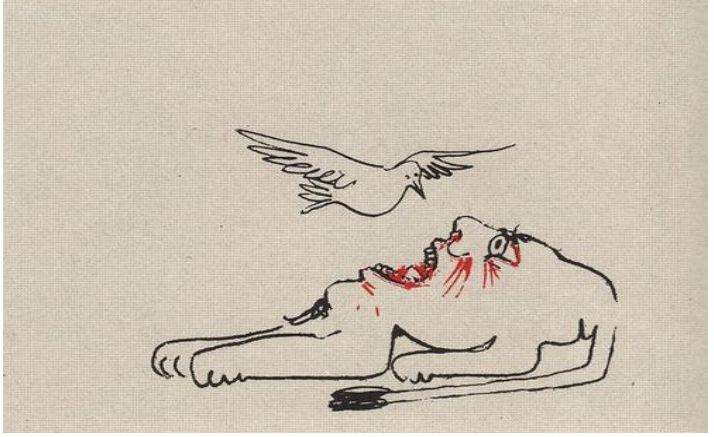

Gambar 3. Penggabungan kucing dengan muka manusia

Dalam CGI tahun 1970-an benar-benar memperoleh pijakan dalam komunitas merancang. Dengan banyak orang bereksperimen dengan teknik film dan merancang teknologi baru dengan cepat berkembang. Hanya beberapa tahun setelah pindah kucing di layar, 2D animator Peter Foldes menciptakan CGI pertama film animasi pendek yang ditarik pada tablet data. Foldes juga menggunakan perangkat lunak frame animasi pertama di dunia key, yang diciptakan oleh Nestor Burtnyk dan Marceli Wein. Untuk pembuatan film, membutuhkan teknologi yang cukup efeisien dan beberapa perangkat pendukung lainnya agar dapat terwujudnya film yang menarik, pengertian film menurut James Monaco (2009:233) mengungkapkan beberapa definisi film. Menurut Monaco, ahli-ahli teori Perancis senang sekali membedakan pengertian film dengan sinema. Film atau "filmis" merupakan aspek seni yang berkenaan dengan hubungannya dengan dunia sekitarnya, sementara sinema "sinematis" lebih mempersoalkan estetika dan unsure internal dari seni film.[11]. Pada zaman modern seperti ini banyak film yang telah dibuat, dalam genre cation, komedi maupun horor. Tidak hanya itu, film juga dikemas dalam genre bernuansa politik dan juga ada yang bergenre dokumenter. Dengan seiring berkembangnya zaman banyak film yang sudah di produksi, dan tentunya menarik untuk di tonton. Film juga bisa mengandung pesan moral positif bagi penontonnya. Industri film ialah industri yang tidak ada habisnya. Sebagai media massa, film digunakan sebagai media yang merefleksikan realitas, atau bahkan membentuk realitas. Cerita yang ditayangkan lewat film dapat berbentuk fiksi atau non fiksi. Lewat film, informasi dapat dikonsumsi dengan lebih mendalam karena film adalah media audio visual. Media ini banyak digemari banyak orang karena dapat dijadikan sebagai hiburan dan penyalur hobi. Salah satunya adalah film Transformers. Sejarah film Transformes dimulai pada Generasi 1 (G1) merupakan serial perdana Transformers yang dirilis pada 1984. Di buat pertama kali tahun 1975 dalam bentuk komik hitam putih. Sebenarnya basis asli Transformers adalah serial mainan Jepang tahun 1970an, Microman dan Diaclone, dimana di mainan-mainan tersebut, yang dalam bentuk robot digambarkan bisa berubah menjadi sesuatu hal seperti mobil, alatalat, dan binatang. Film Transformers versi nyata (bukan kartun) disutradarai oleh Michael Bay. Sementara cerita dibuat oleh Roberto Orci dan Alex Kurtzman. Fokus utama cerita film ini adalah Saibertron yang menyebabkan perang antara Autobots dan Decepticons, dimana dalam film ini yang tersebut adalah Allspark.[4]

Film ini menceritakan Allspark sebagai kubus yang mempunyai energi besar dan dalam menciptakan kehidupan dari benda-benda mekanis. Dalam perang sipil di Saibertron, Allspark secara tidak sengaja terkirim ke Bumi, dan kemudian ditemukan oleh pemerintah AS. Kemudian Hoover Dam dibangun sebagai tempat super rahasia sebagai riset dari pemerintah. Megatron sebenarnya berhasil menyusul Allspark ke Bumi, namun ia jatuh dan mengalami kecelakaan di Artik dan kemudian membeku akibat suhu Artik sebagai kutub utara Bumi. Beberapa tahun 
kemudian ia berhasil ditemukan, dan disimpan di tempat yang sama dengan Allspark. Autobots kemudian juga menyusul ke Bumi dan mencari Allspark. Film ini kemudian menceritakan kehancuran Allspark, dan menyebabkan Autobots tidak bisa lagi kembali ke Saibertron dan mereka sepakat menjadikan Bumi sebagai rumah baru mereka. Film Transformers versi nyata (bukan kartun) disutradarai oleh Michael Bay. Sementara cerita dibuat oleh Roberto Orci dan Alex Kurtzman. Fokus utama cerita film ini adalah Saibertron yang menyebabkan perang antara Autobots dan Decepticons, dimana dalam film ini yang tersebut adalah Allspark.[2]

Film ini menceritakan Allspark sebagai kubus yang mempunyai energi besar dan dalam menciptakan kehidupan dari benda-benda mekanis. Dalam perang sipil di Saibertron, Allspark secara tidak sengaja terkirim ke Bumi, dan kemudian ditemukan oleh pemerintah AS. Kemudian Hoover Dam dibangun sebagai tempat super rahasia sebagai riset dari pemerintah. Megatron sebenarnya berhasil menyusul Allspark ke Bumi, namun ia jatuh dan mengalami kecelakaan di Artik dan kemudian membeku akibat suhu Artik sebagai kutub utara Bumi. Beberapa tahun kemudian ia berhasil ditemukan, dan disimpan di tempat yang sama dengan Allspark. Autobots kemudian juga menyusul ke Bumi dan mencari Allspark. Film ini kemudian menceritakan kehancuran Allspark, dan menyebabkan Autobots tidak bisa lagi kembali ke Saibertron dan mereka sepakat menjadikan Bumi sebagai rumah baru mereka. Dalam versi komik, untuk mendukung cerita film IDW Publishing menerbitkan Transformers: Movie Prequel. Dalam komik ini Optimus Prime menyebut Megatron sebagai saudara, yang kemudian dijelaskan selanjutnya bahwa Optimus dan Megatron adalah pemimpin bersama Saibertron sebelum kelakuan Megatron berubah. Optimus kemudian mengirim Allspark ke Bumi, dan berencana akan menghancurkan Megatron.IDW

Publishing menerbitkan Transformers:

Movie Prequel. Dalam komik ini Optimus Prime menyebut Megatron sebagai saudara, yang kemudian dijelaskan selanjutnya bahwa Optimus dan Megatron adalah pemimpin bersama Saibertron sebelum kelakuan Megatron berubah. Optimus kemudian mengirim Allspark ke Bumi, dan berencana akan menghancurkan Megatron.

\section{Metode Penelitian}

\section{a. Metode Analisa Masalah}

Analisa permasalahan didapatkan dari hasil pencarian yang dilakukan penulis pada hari Rabu 11 Februari 2015 di media internet dan mengunjungi situs resmi teknologi CGI pada pembuatan Film Transformers

\section{b. Metode Pengumpulan Data}

Pengumpulan data dilakukan dengan cara

\section{- Metode Observasi}

Metode yang dilakukan penulis untuk mengumpulkan data dan mendapatkan hal-hal yang diperlukan dalam proses penyusunan laporan penilitian dengan cara mendatangi tempat penelitian secara langsung.

- Studi pustaka

Materi-materi yang dipergunakan sebagai dasar landasan diperoleh dari berbagai sumber tertulis, yaitu buku-buku panduan yang terkait dan memuat informasiinformasi yang diperlukan untuk digunakan dalam penyusunan laporan penelitian. Buku-buku panduan yang dipergunakan penulis dalam halini adalah dari berbagai sumber.

- Interview 
Kegiatan tanya jawab dengan pihakpihak bersangkutan untuk memperoleh informasi guna mendukung kelengkapan dan pengembangan media tersebut.

\section{Implementasi}

Penelitian yang dilakukan oleh Penulis berjudul "Perancangan Media Video Interior Berbentuk Animasi Dengan Menggunakan 3ds Max Pada PT. Utama Mandiri Jaya" .Iklan merupakan pesan yang menawarkan suatu produk yang ditujukan oleh suatu masyarakat lewat suatu media. Dan setelah penulis melakukan analisa terhadap permasalahan yang ada maka terwujudlah sebuah usulan kepada Perguruan Tinggi Raharja untuk membuat sebuah media informasi dan teknologi, yaitu suatu karya film yang dikemas dalam bentuk audio visual efek yang merupakan sebagai media informasi untuk menarik minat masyarakat untuk menjadi lebih tahu tentang teknologi CGI

\section{Program Media}

Film Transformers ini cukup banyak peminatnya, dari kalangan anak-anak sampai kalangan dewasa pun menyukai film bergenre action ini. Film ini memang menampilkan visual efek yang cukup menggagumkan dan bisa dibilang bagus dan luar biasa. Karena pembuatannya pun cukup sulit dan membutuhkan biaya yang tidak sedikit. Dalam pembuatan film ini teknologi CGI sangat berpengaruh dan berperan besr dalam menciptakan efek-efek yang tidak mungkin dilakukan dengan cara manual. Spesial efek yang dihasilkan pun sangat bagus dan seperti nyata.

\section{Tujuan Kreatif}

Teknologi CGI sangat berpengaruh dalam andil besar pembuatan sebuah film. Karena edek yang tidak mungkin di lakukan dengan manual, dengan

Vol.1 No.1 - Agustus 2015 teknologi CGI ini semua adegan dapat dilakukan. Maka dari itu CGI sangat dibutuhkan dalam pembuatan film Transformers ini. Ada banyak alasan yang cukup mengapa film ini hampir semua adegan memakai spesial efek dari CGI ini, di antaranya ;

- Membuat robot yang bertransformasi seperti nyata atau asli

- Perubahan bentuk mobil ke robot yang terlihat halus tanpa ada kesalahan

- Melakukan perjalanan ke luar angkasa, dalam sekuel Transformers 3 : Dark of The Moon

\section{Tujuan Visual}

Dimana tujuan visual ini menjelaskan tentang bagaimana suasana dan aktifitas pada pembuatan film Transformers ini. Di sini juga di jelaskan teknik dan efek apa saja yang digunakan. Mulai dari software dan alat-alat keperluan syuting tidak luput dari penjelasan tujuan visual ini. Penjelasan yang akan diterangkan oleh penulis adalah bagaimana cara membuat efek dalam CGI terlihat nyata setelah proses syuting. Dan hasilnya pun dapat dinikmati oleh semua orang. Dengan kata lain dikatakan sebagai nedia promosi dan informasi agar dapat berguna nantinya.

\section{Proses Pengambilan Gambar}

Pada proses ini sangatlah penting dalam pengambilan gambar, karena berdasarkan keperluan syuting. Proses ini juga berpengaruh padapengambilan efek di green screen dan akan di teruskan ke proses CGI nya. Dalam hal ini perencanaan yang teratur untuk mencapai kesempurnaan sangat penting untuk diperhatikan. 


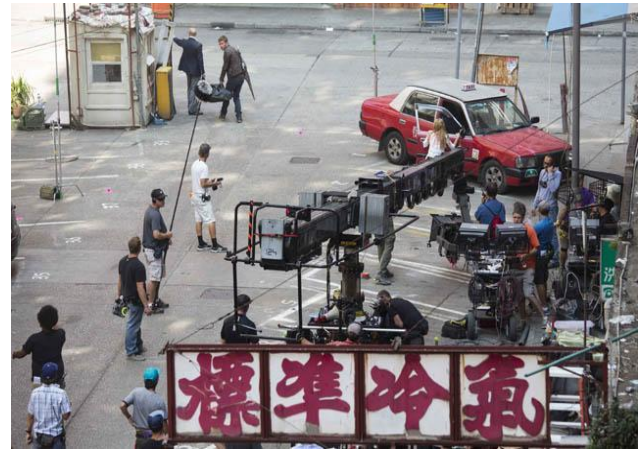

Gambar 4. proses pengambilan scene di china

\section{Gambar proses dari hasil Computer Generated Imagery}

Dari beberapa pengambilan gambar, proses menggunakan green screen juga harus dilakukan. Karena ada adegan pengambilan gambar yang tidak mungkin dilakukan pada proses pengambilan manual. Untuk itu teknologi yang digumakan dalam CGI harus akuran dan tepat.

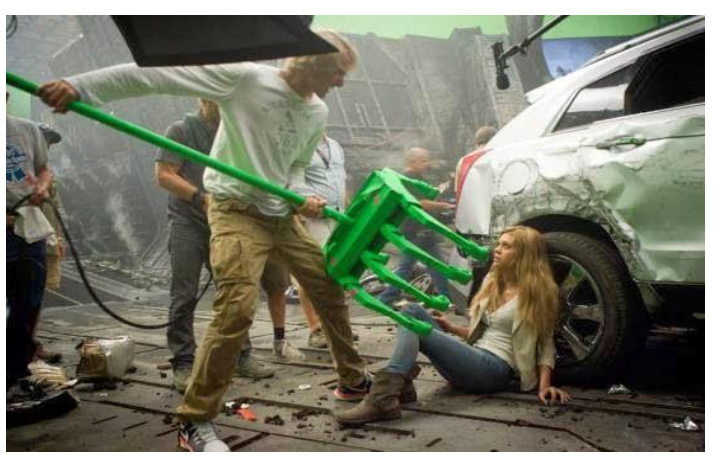

Gambar 5. Proses pengambilan tangan decepticon dalam green screen

\section{a. Proses pengambilan pertama CGI}

Dalam proses ini bermula saat adegan pemain dan robot ada dalam satu tempat dan divisualisasikan dengan konsep dunia nyata.

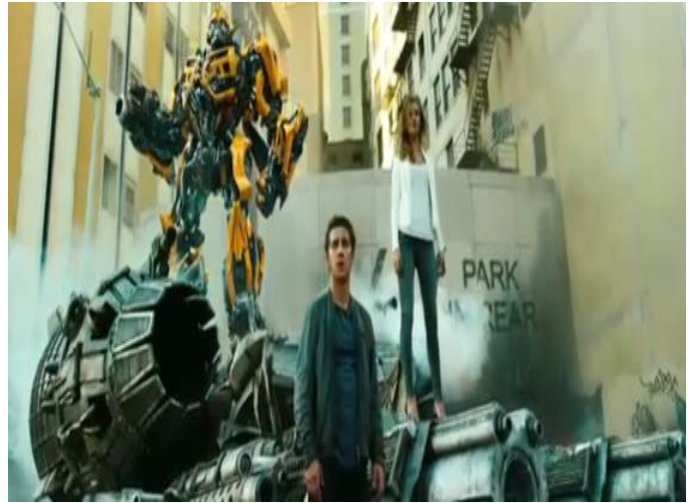

Gambar 6. Konsep penyatuan CGI dengan kondisi sebenarnya

b. Proses perubahan mobil menjadi robot

Proses Transformasi ini sudah tentu akan menggunakan CGI, karena akan ada beberapa efek yang akan ditampilkan.

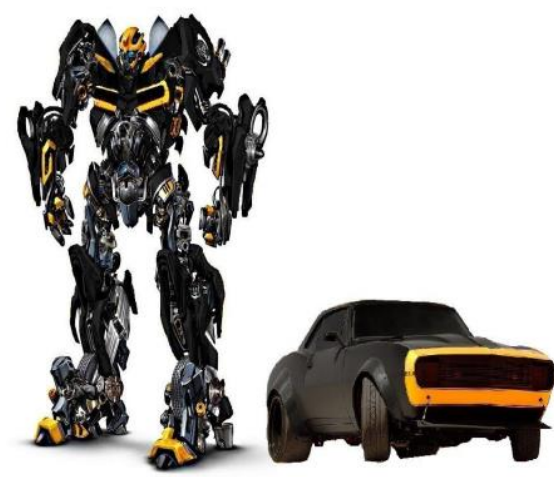

Gambar. 7 Tranformasi mobil dan robot

\section{c. Proses penerapan CGI}

Pada tahap ini, semua pengambilan gambar dan adegan dilakukan dalam green screen lalu akan di edit dan di perhalus agar masuk dalam adegan yang sebenarnya. 

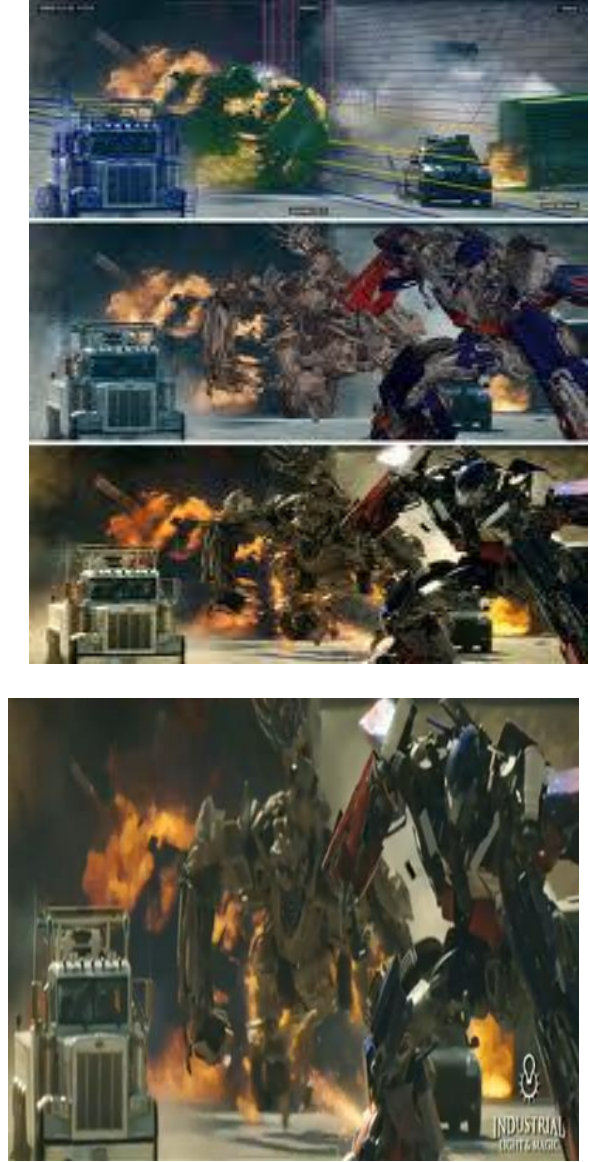

Gambar 8. Hasil dari penerapan CGI ke dalam dunia nyata

\section{d. Proses pengambilan dari green screen}

Pada proses ini, adegan yang tidak bisa di ambil dalam pengambilan manual akan dilakukan dengan cara menggunakan teknologi dari green screen. Seperti contoh saat melakukan perjalanan ke bulan dan pesawat Alien yang terjatuh.

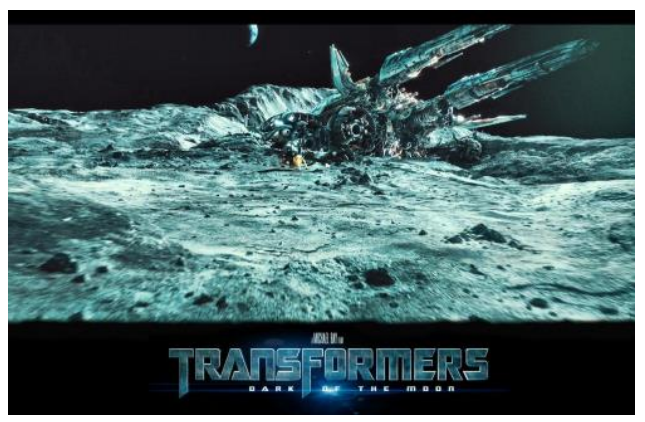

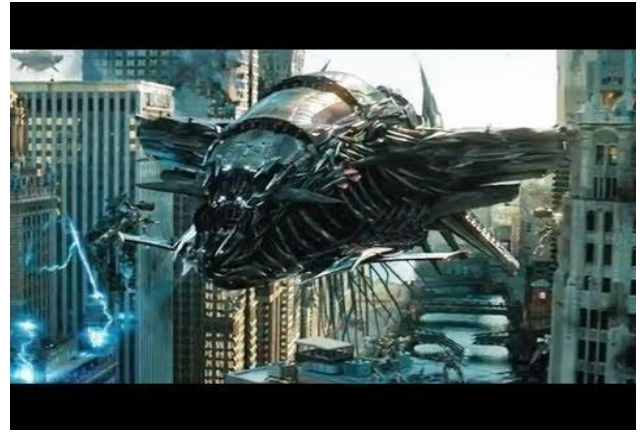

Gambar 9. Background dari

Transformers 3 : Dark Of The Moon

\section{e. Proses hasil analisa pada CGI}

Dengan adanya hal ini, beberapa adegan tidak mungkin dilakukan dalam satu atau sekali pengambilan gambar. Tetapi dilakukan berkali-kali sampai hasil yang ingin dicapai sesuai dengan target atau sampai benarbenar terlihat nyata.

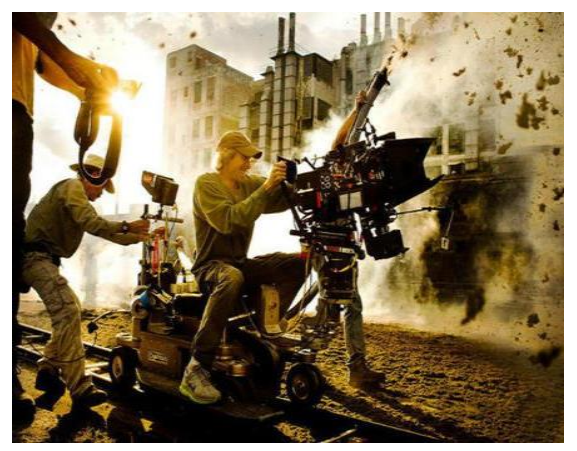

Gambar.10 Suasana syuting pengambilan gambar pada CGI

\section{f. Proses Tahap Editing}

Pada tahap terakhir ini adalah proses editing. Penggabungan gambar dari awal sampai akhir dan di gabungkan menjadi satu gambar utuh dengan durasi tertentu. Pada tahap ini proses render juga di lakukan agar gambar yang dihasilkan cukup bagus. Dengan menggunakan perangkat lunak komputer maka proses editing akan segera 
berjalan dengan jadwal ataupun daftar yang sudah di sesuaikan.

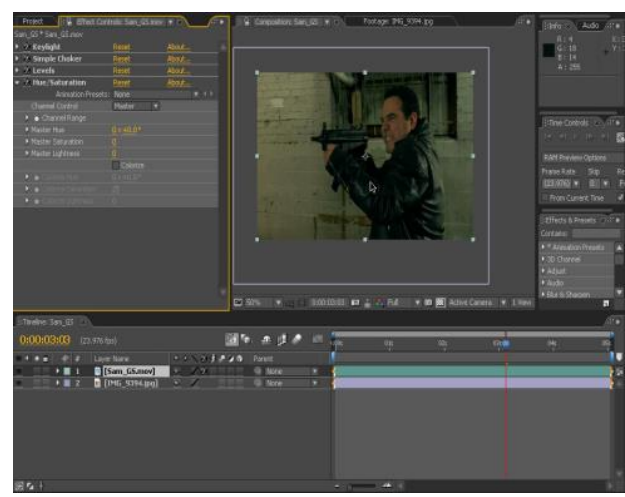

Gambar 11. Hasil editing pada adobe premiere

\section{Final Proses Computer Generated Imagery}

Final Proses Computer Generated Imagery adalah merupakan tahap dari pengambilan gambar dari awal sampai akhir yang dilakukan pada proses sebelumnya. Dalam tahap ini semua proses pengambilan gambar sudah selesai namun akan memasuki proses selanjutnya yaitu editing dan penempatan efek suara maupun adegan perubahan robot dan yang lainnya.[1]

\section{a. Proses hasil penerapan Teknologi CGI}

Pada tahap ini proses hasil dari CGI dan green screen akan ditampilkan dalam keadaan yang seperti nyata, dimana ada adegan robot dan manusia yang sedang dalam satu tempat. Pada tahap ini, hasil dari editing dan penmabahan efek suara maupun yang lainnya sudah diterapkan.
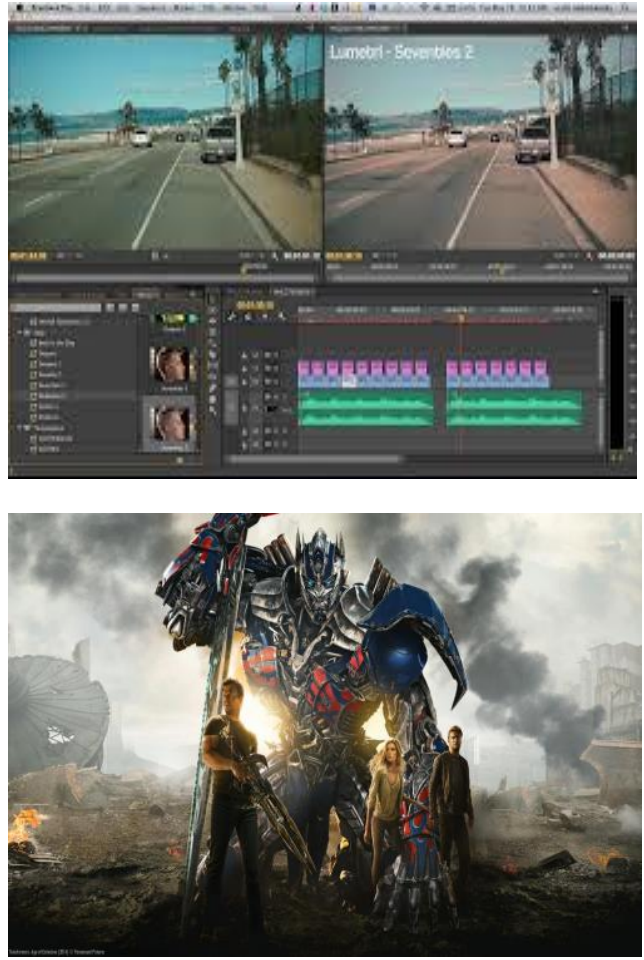

Gambar 12. Hasil penggabungan Teknologi CGI dengan green screen

b. Penerapan hasil efek di teknologi CGI

Efek yang dihasilkan pada tahap editing pun juga tidak sembarangan, karena harus sesuai dengan gambar. Dalam proses ini tahap CGI memegang peran penting dalam penentuan ritme dan tempo suara yang dihasilkan. Agar dapat gambar dan suara yang jernih dan pas.

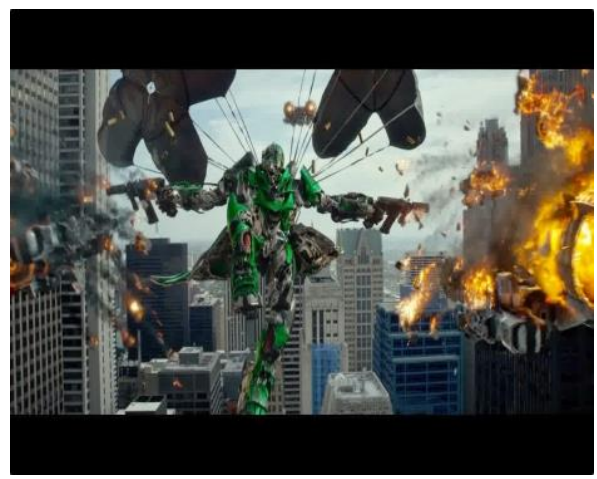

Gambar 13. Spesial efek pada pertempuran Transformers 


\section{c. Tampilan Hasil semua Teknologi CGI dan Green Screen}

Hasil semua tampilan yang telah di edit dan di render sedemikian rupa hingga menghasilkan sebuah film yang menakjubkan dari teknologi modern Computer Generated Imagery yang di padu dengan metode green screen. Pada hasil yang telah jadi, semua elemen dalam teknologi CGI sudah dibersihkan, dan tampak halus seperti tidak ada yang kurang. Pada proses ini editor bertanggung jawab penuh dengan hasil yang akan segera di tayangkan. Jika ada kesealahan dalam proses editing maka teknologi CGI akan berpengaruh pada film Trasnformers ini. Film Transformers ini cukup banyak menggunakan teknologi CGI dan metode penggambilan gambar dengan green screen.[13]

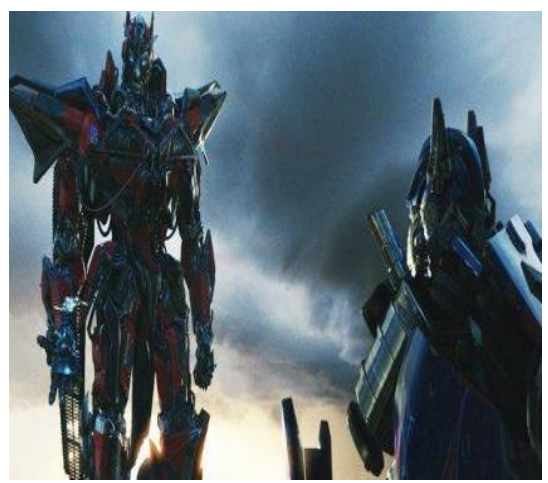

Gambar 14. Hasil dari semua teknologi CGI

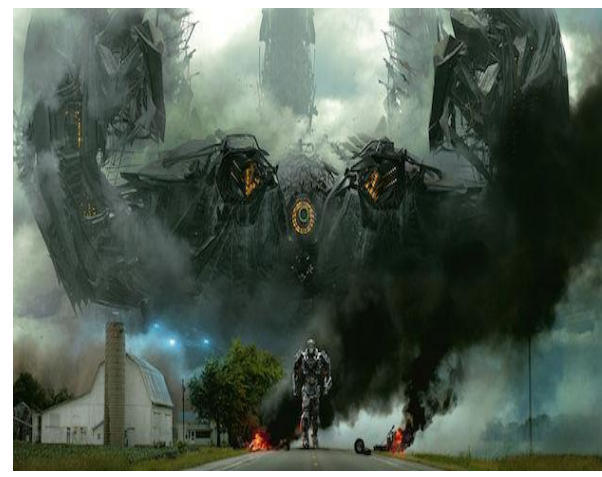

Vol.1 No.1 - Agustus 2015
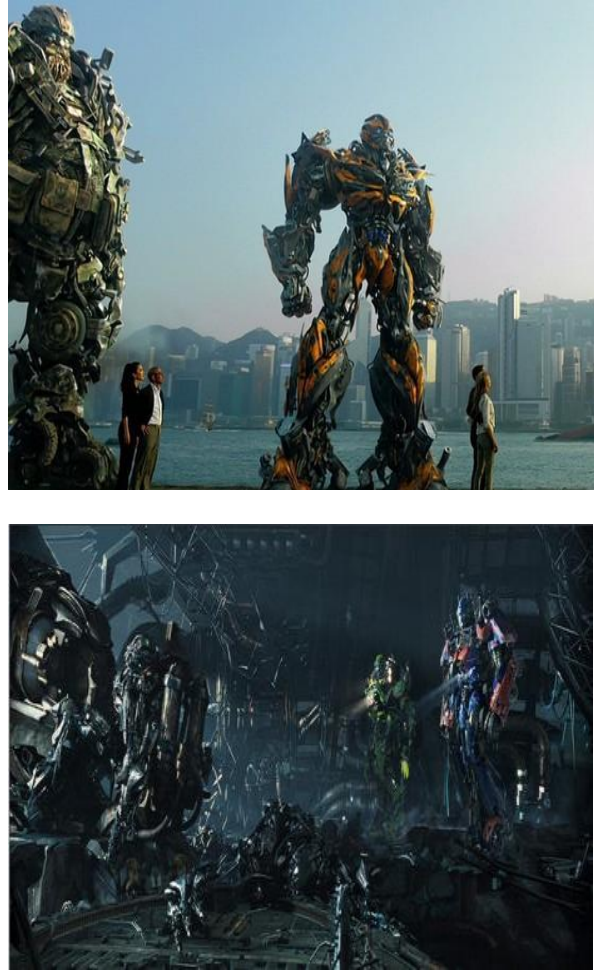

Gambar 15. Hasil beberapa Teknologi CGI, dan terlihat nyata

\section{Kesimpulan}

Berdasarkan hasil penelitian tentang manfaat teknologi CGI pada pembuatan film, penulis mengemukakan bahwa teknologi CGI ini sangat berpengaruh pada setiap pembuatan film. Karena pada zaman modern saat ini kebutuhan film sangat meningkat drastis. Maka dari itu penerapan teknologi ini sangat berpengaruh pada konsep pembuatan film. Sama halnya dengan film Transformers ini yang banyak menggunakan teknologi CGI.

Dengan adanya teknologi CGI ini, pembuatan film dengan pengambilan manual yang hampir tidak bisa dilakukan dan hanya bisa dilakukan dengan penerapan teknologi CGI ini dan metode penggunaan green screen. Pada tahap penerapan teknologi CGI ini bisa memangkas waktu, dan tidak memakan waktu yang terlalu banyak. Dari segi biaya mungkin teknologi CGI ini cukup mahal dan membutuhkan komputer dan alat-alat syuting yang tidak sedikit. Dan 
juga penerapn CGI ini tidak hanya dalam sekali pengambilan take gambar.

Dalam membuat film Transformers ini, harus memperhatikan faktor-faktor yang berhubungan dengan robot dan perjalanan fiksi mengarungi luar angkasa. Dalam hal ini, sang sutradara berperan penting dalam menentukan alur cerita dan penentuan naskah dengan script writter. Untuk membuat film yang bagus dan menarik, semua orang yang terlibat dalam pembuatan film ini harus saling berkerja sama dan menyampingkan ego mereka masing-masing.

\section{Daftar Pustaka}

1] Bina Nusantara University Library, (2011) Pemanfaatan Computer Generated Imagery di akses pada tahun 2008

[2] Dean Foster, Alan; David Cian, “ TRANSFORMERS: GHOSTS OF YESTERDAY, DEL RAY " Books, Page(S) : 286, ISBN 978-0-345-49798-7.

AlphaScript Publishing : Amerika Serikat, 2007

[3] Gonzales Rowan, “ A COMPUTER GENERATED HISTORY

http://computerstories.net/a-computergenerated-imagery-cgi-history/ di akses pada tanggal 11 May 2011, Amerika Serikat

[4] Hasbro Publishes Transformers Timeline to Movie". TFormers. 2007-0209. Diakses 2007-02-10.

[5] Hidayat Wahyu, Hiadayat Wahyu, Rachnatullah Farhan, "PERANCANGAN MEDIA VIDEO INTERIOR BERBENTUK ANIMASI DENGAN MENGGUNAKAN 3DS MAX “ Jurnal CCIT Vol. 7 No. 2 Januari 2014, Perguruan Tinggi Raharja: Indonesia, 2014

[6] Maimunah, Sunarya Lusyani, Suharmianti, " DESAIN COMPANY PROFILE INTERAKTIF SEBAGAI MEDIA INFORMASI DAN PROMOSI
BERBASIS WEB APLIKASI DAN CD INTERAKTIF “ Jurnal DIGIT Vol. 1 No. 1 Mei 2011, Lembaga Penelitian Dan Pengabdian kepada Masyarakat : Indonesia, 2011

[7] Miarso, " MENYEMAI BENIH TEKNOLOGI PENDIDIKAN “ Books, Page (S) : 62, Kencana, diterbitkan atas kerja sama dengan Pustekkom-Diknas : Jakarta, Indonesia, 2007

[8] Miller P. Frederic, Vandome F. Agnes, McBrewster John, "COMPUTER-GENERATED

IMAGERY: COMPUTER GRAPHICS, 3D COMPUTER GRAPHICS, SPECIAL EFFECT, FILM, TELEVISION PROGRAM, TELEVISION ADVERTISEMENT, SIMULATION, VIDEO GAME, CUTSCENE "Books, Page(S) : 57-59, AlphaScript Publishing : Amerika Serikat, 2010

[9] Mitchell A. J. , “ VISUAL EFFECT FOR FILM AND TELEVISION “, Books, Page(S) : 40, Taylor and Franciss :Bournemouth University,england, 2005 [10] Monaco James, "HOW TO READ A FILM: MOVIES, MEDIA, AND BEYOND: MOVIES, MEDIA, AND BEYOND “ Books, Page(S) : 568-570, Oxford University : Wellington Square, England, 2009

[11] Monaco James, "HOW TO READ A FILM: MOVIES, MEDIA, AND BEYOND: MOVIES, MEDIA, AND BEYOND “ Books, Page(S) : 233, Oxford University : Wellington Square, England, 2009

[12] Rahardja Untung, "KPM SEBAGAI PEDOMAN PRODUKSI MEDIA MULTIMEDIA AUDIO VISUAL AND BROADCASTING "Jurnal CCIT Vol. 3 NO. 2 Tahun 2010

[13] Suprapto Tommy, "BERKARIER DI BIDANG BROADCASTING “ Books, Page(S) : 78 Media Pressindo : Yogyakarta, Indonesia, 2010 